\title{
Research and Implementation of digital Ceramics Museum based VRML
}

\author{
Hua Huang ${ }^{1}$, Yi-Lai Zhang ${ }^{2}$, Min Zhang ${ }^{3}$ \\ 1,2,3 Jingdezhen Ceramic Institute,Jingdezhen, Jiangxi, 333001, China \\ 1jdz_hh@qq.com, 22jdzzyl@qq.com, ${ }^{3} 191148074 @ q q . c o m$,
}

\begin{abstract}
In this paper, VRML virtual modeling language and WEB2.0 technology are used to build a network platform for digital Ceramics Museum, By use of digital art knowledge, combined with information technology tools, computer network technology, communication technology and image acquisition technology, collection of specimens were digitized, meanwhile using a different depth level of content and performance language to book data, plan content and process artistic, it is possible to create out a threedimensional virtual museum as well as internal exhibits, in which ceramic relics, ceramic arts, other some valuable exhibits in museums and the firing process of ceramics in the ancient firewood kilns (dragon kilns, gourd, kiln, etc.) and modern gas kiln is given threedimensional digital display.
\end{abstract}

Index Terms - Digital ceramic museum; virtual museum; VRML;WEB2.0.

\section{Introduction}

Digital works have come into various aspects of human life with the popularity of computer and network development, Project of University Digital Museum created by the Ministry of Education is a forward-looking initiatives. Digital information of our University Museum is both conducive to the protection of our cultural heritage of the area of education, but also useful to strengthen the exchanges and cooperation between domestic and foreign experts in the field, and of great significance to play its inherent advantages in educational resources and to promote the development of education.

The traditional digital museums are referred to make digital information and multimedia information database for its long-term accumulation of collections and exhibitions and to spread out the information by using the Internet. In fact, the display of the "digital museum" in some sense is still twodimensional. With the development of virtual reality technology, a new breakthrough has occurred in the field of three-dimensional modeling, so that the three-dimensional museum became a reality. Foreign digital virtual museums started earlier than China and have a more mature technology. More than 200 museums are well known such as British Museum, American Art Museum, and Beijing Palace Museum and so on, most of the word museums provide overviews of museum and browses of exhibitions, collections, academic, service, dynamic navigation and search by using common Web browser. The Beijing Palace Museum, which is completed on August 1, 2001, is one of the first batch of whose database is put onto the Internet, but now a real sense digital Ceramics Museum have not existed. Digital network of Jingdezhen Ceramics Museum did not truly realize the pottery craft scene reproduction of traditional kiln and kilns, three display and multi-media interactive features of the museum and exhibits.

Ceramics is the great inventions of ancient China; Jingdezhen Ceramic is the quintessence of our national industry and culture, whose level has high reputation in the world. In order to make use of Jingdezhen natural and human resources and protect the Jingdezhen ceramics cultural heritage, the importance of accelerating the digitization process of the local ceramics museum is obvious.

In this paper VRML technology and advanced network technology is used to achieve the digitization of Ceramics Museum, digital ceramic museum constructed in the project can promote multimedia technology to enter a new phase in the comprehensive display of the ceramic culture and to translate functions of collecting, saving, study and dissemination of traditional ceramics museum from real space into the unlimited extension of the virtual space, which will bring infinite vitality for Jingdezhen Ceramics Museum.

\section{Content of Research}

\section{A. Requirements analysis}

To analysis the inadequacies that Jingdezhen Ceramics Museum displays historical relics and cultural knowledge for the audience, at the same time, a large number of treasures living on private and overseas can not enter the museum for exhibitions and exhibits of pottery technology can not be realtime shown to the audience, digital necessity and urgent needs of building the ceramics Museum is obtained.

\section{B. Functional Analysis}

Use VRML and advanced WEB2.0 network technology to build digital ceramic museum network platform, realize the acquisition and storage of ceramics culture, ceramic art, ceramic art production process and other related available information at the full range and to provide online enjoying and learning services for the audience by a variety of ways such as virtual museums, multimedia interactive network communication, on-site player, information queries, and so on. Its main function is as follows:

(1) Use VRML, 3D Max, Flash and other software technologies to achieve the pottery craft scene representation of the traditional kiln kilns, three-dimensional display of ceramic works and multimedia interactive features.

1) Cultivating image animation; (2D FLASH animation)

2) Evolution and display of several large kilns and; (3D display) 
3) Combustion process of ceramics in the kiln fire, a threedimensional form of the furnace heating up; (3D display)

4) Virtual tour of the virtual Kilns; (the origins, history of Kilns, etc.)

5) Concentrated display of representative pottery works according to the dynasty; (3D display) 6) Pottery technology and process of modern ceramic; (Video, Photos)

7) Culture appreciation of porcelain and ceramics;

(2) Make integrated use of multimedia design software with VRML technology, to achieve virtual reality and interactive features ,to make the audience to visit and understand information and background of ceramic artefacts and ceramic art exhibits by themselves and improve the deficiencies in the traditional physical museum exhibitions.

(3) Make use of 3DMAX software and VRML, WEB2.0 to simulate the visiting process to stage performances and to complete a multimedia presentation works with interactive features.

(4)Develop functionality of online interactive experience designed for ceramic products in the digital Ceramics Museum.

\section{Design and implementation of this System}

\section{A. Architecture of this system}

Web-based virtual showroom is required to be built on the Internet; a three-dimensional computer model of Jingdezhen Ceramics Museum is presented in front of the viewers. The overall structure of this system is shown in Fig.1.
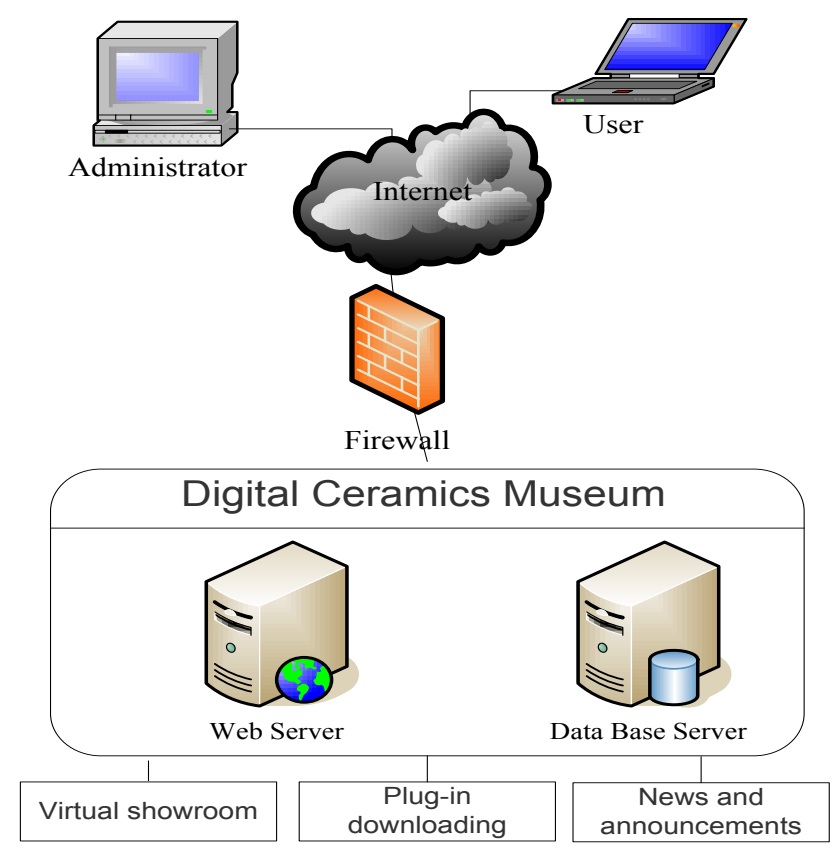

Figure1. Overall structure of this system

\section{B. Design of System Function}

This system is a website system with B / S structure, which can be divided into foreground and background part. The frontier of this system is used to publicly release the contents of the virtual museum, which includes virtual showroom, plugin downloading, modules of news and announcements. The main part is the virtual exhibition hall, which is built by using VRML virtual modelling language. Administrators of this system can $\log$ into the backend system and modify the files in this system

\section{Design of virtual exhibition}

The system is consisted of multiple virtual showrooms, such as the virtual showroom of ceramic kilns, ceramic artefacts, the virtual exhibition of ceramic culture, the virtual exhibition hall of pottery works, now as an example the virtual exhibition of ceramic kilns is introduced as below, whose frame structure is shown in Fig. 2

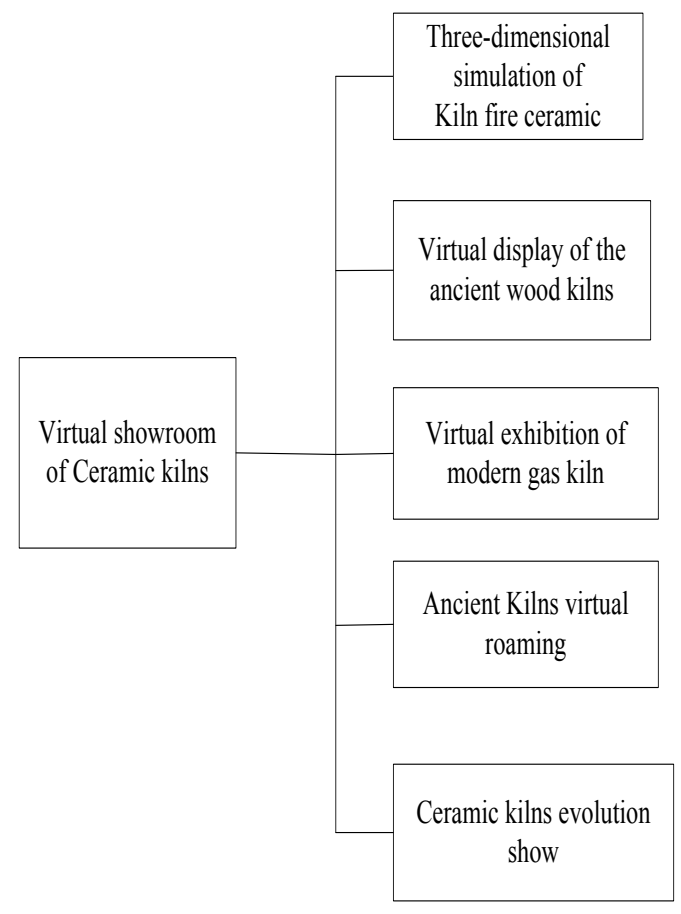

Figure2. Framework structure of the virtual exhibition of ceramic kilns

\section{Modeling of virtual showroom}

Firstly, it is necessary to plan a blueprint of exhibition hall, according to the blueprint related child objects are created, meanwhile pictures and audio and video data needed to be collected. Secondly according to the characteristics of the relevant sub-object to select $2 \mathrm{D}$ or $3 \mathrm{D}$ display, make model and paste texture. Lastly make use of a good model collection to generate the final virtual showroom. The system uses the edit method of VMRL Pad to build the model[1] [2]. VRML Pad is a very good virtual reality file editor, which not only can improve the efficiency of writing code, but also can provide a debugging feature of programming, and is one of the essential weapons to complete a complex virtual scene. The flow chart of modelling is shown in Fig.3. 


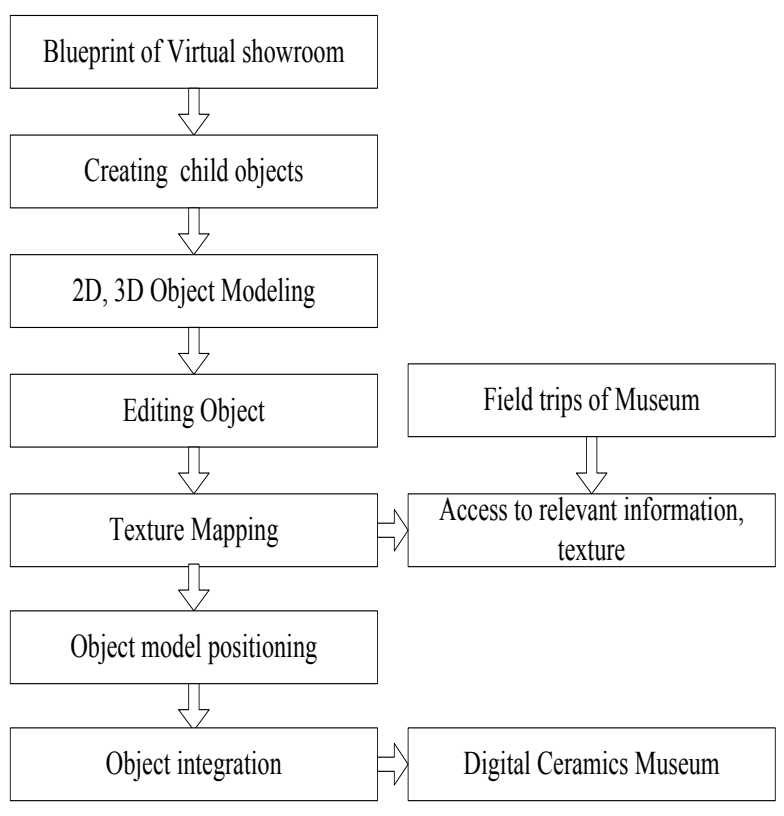

Figure 3. Modeling process of Digital Ceramics Museum

\section{E. Modeling of virtual showroom}

VRML language is designed to achieve three-dimensional world on the Internet, after the scene are designed completely, the work is published to the Internet. VRML can very easily embed elements into the html document, "embed" is used for the introduction of various objects, including video, sound, and also VRML, a combination of both can produce a page with dynamic effects[3] [4] [5], In this system VRML technology and WEB2.0 technology is used to integrate the virtual showroom on the network platform.

\section{Conclusions}

In this paper, this system will make comprehensive use of a variety of multimedia design software and VRML technology and WEB2.0 technology, to achieve better virtual reality and interactive features, implement new visual experience of the digital Ceramics Museum and a experience of visit by means of multimedia technology and finally create network display platform of virtual pottery and ceramic culture integrated with multimedia interactive actions. It is extremely important to transform ceramics Museum by digital means, to share resources and protect the precious resources of the ceramics Museum.

\section{Acknowledgment}

This work was supported by National Science and Technology Support Program .(NO.2012BAH25F02 and No. 2013BAF02B01)

\section{References}

[1] Nowka K J, Carpenter G D, Brock B C. The Design and Application of PowerPC 405LP Energy-efficient System-on-a-Chip[J]. IBM Journal of Res. \& Dev., 2003, 47(5/6): 631-639.

[2] Mudge T. Power: A First-class Architecture Design Constraint[J]. IEEE Computer, 2001, 34(4): 52-58.

[3] Liu Yi, Zhang HongDing, Cui Xin. VRML programming [M]. Tianjin: Nankai University Press, 2007:1 -3.

[4] Shen Jiang-Wei, Chen Tian-zi. VRML system framework based on multiuser environment [J]. Computer Engineering and Design, 2005,26 (10) :2654-2656.

[5] Ma Xiurong, design and demonstration of building models in the scene based on VRML [J]. Changchun: Jilin University,2006:31 -32. 